\title{
Article \\ Vibrations Induced by Mechanical Rock Excavation on R.C. Buildings in an Urban Area
}

\author{
Valeria Leggieri *(D), Annamaria di Lernia (D), Gaetano Elia (D), Domenico Raffaele (D) and Giuseppina Uva (1D \\ Department of Civil, Environmental, Land, Building Engineering and Chemistry (DICATECh), \\ Technical University of Bari, via Orabona 4, 70125 Bari, Italy; annamaria.dilernia@poliba.it (A.d.L.); \\ gaetano.elia@poliba.it (G.E.); domenico.raffaele@poliba.it (D.R.); giuseppina.uva@poliba.it (G.U.) \\ * Correspondence: valeria.leggieri@poliba.it
}

Citation: Leggieri, V.; di Lernia, A.;

Elia, G.; Raffaele, D.; Uva, G.

Vibrations Induced by Mechanical Rock Excavation on R.C. Buildings in an Urban Area. Buildings 2021, 11, 15. https://doi.org/10.3390/

buildings11010015

Received: 30 November 2020 Accepted: 28 December 2020 Published: 31 December 2020

Publisher's Note: MDPI stays neutral with regard to jurisdictional clai$\mathrm{ms}$ in published maps and institutional affiliations.

Copyright: () 2020 by the authors. Licensee MDPI, Basel, Switzerland. This article is an open access article distributed under the terms and conditions of the Creative Commons Attribution (CC BY) license (https:// creativecommons.org/licenses/by/ $4.0 /)$.

\begin{abstract}
The paper describes the numerical approach adopted to investigate the effects of vibrations induced on reinforced concrete (R.C.) buildings by the excavation works needed to bury an existing railway line crossing an urban area in the south of Italy. The construction works are carried out in dolomitic rocks, characterized by a high resistance to excavation. Therefore, they may have a great impact on the surrounding environment in terms of induced vibrations. The study is conducted through an uncoupled approach, investigating the dynamic response of the geotechnical system and the above-surface structure, separately. The impulse force equivalent to the dynamic action of a breaker hammer is used as input motion for 2D finite element (FE) geotechnical simulations of the wave propagation process occurring during the excavation. Then, the acceleration time histories obtained from the geotechnical analyses are adopted to study the dynamic performance of an "index" R.C. building, representing the most recurrent structural typology in the examined area, through a 3D FE model. The results show how the adoption of a mitigation strategy consisting in the execution of a preliminary vertical cut followed by a rock crushing treatment allows to significantly reduce the vibrations induced by the excavation processes on existing buildings.
\end{abstract}

Keywords: construction-induced vibrations; FE modelling; uncoupled approach; dynamic analysis

\section{Introduction}

It is well recognised that, during civil engineering construction works in urbanized areas, blasting, pile driving, hydraulic machinery, and production equipment generate vibrations in the surrounding environment which may cause damages on the nearby buildings and nuisance to the neighbouring population [1].

In particular, the excavation activities, involving the removal of soil and rock through blasting or mechanical tools, can induce dynamic loads on the adjacent structures, and the generated ground vibrations may have detrimental effects on the residents in the surrounding environment [2,3]. For this reason, when the excavation works are located in an urban area, the adoption of non-explosive mechanical methods, such as hydraulic breaker hammers, can be more convenient, as they have a lower impact on the sensitive receptors on the ground surface.

The various effects of the excavation works on the surrounding sensitive receptors are still not fully investigated in the research literature, due to the complexity of the problem [4]. Indeed, the level of induced vibrations depends on several variables such as the excavation method, the nature of the used equipment, the properties of the subsoil material, the heterogeneity of the soil deposit, the distance of the sensitive receptor from the source of vibration, and the dynamic characteristic of the adjacent structures [5]. Therefore, the analysis of this problem requires different geotechnical and structural engineering skills. From a geotechnical perspective, it resembles the study of ground-induced vibrations due to the passage of high speed trains conducted in the railway engineering field [6-8]. From a structural point of view, the vibrations generated by different types of construction 
equipment can be assessed using various approaches, including controlled experiments, direct measurements and predictions obtained through analytical, empirical equations, or numerical analysis [9-13]. In general, the effects on the buildings are evaluated in terms of particle displacement, velocity, and acceleration time histories, described by two horizontal (transverse and longitudinal) and one vertical component [14-16].

Several international standards, among which the German Standard DIN 4150-3:1999 [17], the British Standard BS 7385-2:1993 [18], the British Standard BS 5228-4:1992 [19], and the Swiss Standard VSS-SN640-312a:1992 [20], provide the criteria for the measurement of vibrations and the assessment of their structural effects by fixing, for different categories of buildings, a maximum threshold of the peak component particle velocity ( $p c p v)$, assumed as the most appropriate parameter to consider in the analysis. In the Italian context, the UNI 9916:2004 [21] and the NTC 2018 [22] present the corresponding standard code requirements.

When the levels of vibrations, generated by hydraulic breaker hammers in the rock fragmentation process, on a sensitive receptor are higher than the limit values provided by the standards, an effort should be done to attenuate the ground movements through appropriate mitigation strategies. Within this context, the adoption of non-explosive technologies to weaken hard rock deposits, based on physical and chemical processes, is increasingly spreading in the engineering practice. Amongst the others, an efficient and operational method is the one based on the use of a carbon dioxide cracker. The method consists in converting the liquid carbon dioxide into an inert gas through a chemical heater [23]. The conversion expands the $\mathrm{CO}_{2}$ volume and builds up the pressure inside a tube, introduced within the rock to be fragmented, until it causes a rupture disc at the end of the tube itself. The carbon dioxide gas based technology is, nowadays, deemed to be safe and represents a feasible alternative to standard mechanical excavation methods [23-25].

This paper presents the results of an uncoupled numerical approach adopted to simulate and quantify the effects of the vibrations induced on the ground deposit and, consequently, the surrounding buildings by different rock excavation techniques. The numerical investigation refers to a realistic case study, where the excavation works in hard rock masses were needed to bury an existing railway line in an urbanised area. The approach consists in the evaluation of the wave propagation process due to rock excavation through a 2D finite element (FE) geotechnical model. Due to the high resistance to excavation of the rock mass, different excavation techniques (i.e., hydraulic hammer, preliminary vertical cut, carbon dioxide cracker) are considered in the geotechnical analyses to quantify the construction-induced ground vibrations. Then, the ground vibrations obtained from the geotechnical model are applied as input motions at the base of the structure and the dynamic response of an "index" reinforced concrete (R.C.) building, selected as the most recurrent structural typology in the examined area, is investigated through 3D FE structural simulations. The building response to the base excitations is assessed in different points of the structural model in terms of $p c p v$ and maximum displacement, whose thresholds are given by the technical standards. This allows to evaluate the effectiveness of the mitigation strategies adopted, in the specific case, to reduce the vibrations of the building due to the ground excavation works.

\section{Description of the Case Study}

\subsection{Geological and Geotechnical Model}

The paper describes the excavation works needed to bury an existing railway line crossing the urbanized area of a municipality in the Apulia region (South-East Italy). The project consists in the construction of deep sub-vertical trenches, very close to existing roads and buildings, excavated in rock masses through mechanical breaking methods. Due to the strategic relevance of the engineering works, the site was extensively investigated through geological and geotechnical campaigns, carried out along the layout of the railway line, consisting in 10-40 m deep continuous coring boreholes, SPT, and down-hole tests. 
The local geological area is characterized by the presence of uniform and homogeneous limestone, dolomitic limestone, and dolomite rock formations under a shallow layer of soils. Only locally, few meters of sands and loose materials are detected. The hydrogeological investigation reveals the presence of a very deep water table, not interacting with the designed structure.

The analysis and interpretation of the geotechnical investigations allowed to recognize four lithotypes: the first (GL1) consists of a shallow layer of vegetable topsoils and backfills, comparable to a sandy silt in terms of particle size distribution. Due to its small thickness (around 1-2 m), the GL1 layer has a marginal role in the design of geotechnical structures. The second lithotype (GL2) is characterized by fine-grained sands interlayered by coarsegrained calcarenites, extending on a relatively limited area along the railway route. The third geotechnical lithotype (GL3) is formed by highly fractured calcareous rocks, while the fourth (GL4) consists of medium fractured limestones and dolomitic limestones. Along the whole layout of the railway, the lithostratigraphic profiles are mainly characterized by the presence of the GL3 layer alternating with the GL4 stratum.

Typical values of the mechanical properties of the GL1 and GL2 soil layers were assumed in the analysis. For the GL1 soil, the unit weight $\gamma$ was set equal to $18 \mathrm{kN} / \mathrm{m}^{3}$, while the effective friction angle $\varphi^{\prime}$ was assumed to be equal to $28^{\circ}$; the GL2 layer is, instead, characterized by $\gamma=18 \mathrm{kN} / \mathrm{m}^{3}$ and $\varphi^{\prime}=32^{\circ}$. For the rock layers (i.e., GL3 and GL4), the strength parameters were determined on the basis of the rock masses classification proposed by Bieniawsky [26]. For each lithotype, a value of the RMR (Rock Mass Rating) was identified considering the uniaxial compressive resistance of the intact rock, RQD (Rock Quality Designation) of the rock mass, openings of joints, joint conditions, hydraulic conditions, and discontinuity orientations. A value of 28 was obtained for the RMR index of the GL3 material, thus classifying it as "poor rock" (class IV-characterized by an effective cohesion between 100 and $200 \mathrm{kPa}$ and $\varphi^{\prime}$ ranging between $15^{\circ}$ and $24^{\circ}$ ). Therefore, the values of $c^{\prime}=100 \mathrm{kPa}$ and $\varphi^{\prime}=25^{\circ}$ were assumed representative of the GL3 rock strength. The GL4 lithotype, with a RMR equal to 60, can be designated as "fair rock" (class III-characterized by $c^{\prime}=200-300 \mathrm{kPa}$ and $\varphi^{\prime}=25^{\circ}-35^{\circ}$ ). The strength parameters for the GL4 rock were set to be $c^{\prime}=200 \mathrm{kPa}$ and $\varphi^{\prime}=35^{\circ}$. In both cases, a unit weight of $24 \mathrm{kN} / \mathrm{m}^{3}$ was assumed as a typical value for rock masses. A summary of the mechanical parameters adopted for the different materials is reported in Table 1. The table includes the average value of the shear wave velocity vs. estimated from the available down-hole tests and associated to each lithotype.

Table 1. Different materials recognized from the geotechnical investigations.

\begin{tabular}{cccccc}
\hline & Description & $\gamma$ & $c^{\prime}$ & $\boldsymbol{\varphi}^{\prime}$ & $V_{\mathbf{s}}$ \\
\hline $\mathbf{G L 1}$ & Vegetable topsoils and backfills & 18 & 0 & 28 & $\mathbf{k N / \mathbf { s }}$ \\
\hline $\mathbf{G L 2}$ & $\begin{array}{c}\text { Fine-grained sands interlayered by } \\
\text { coarse-grained calcarenites }\end{array}$ & 18 & 0 & 32 & 436 \\
\hline $\mathbf{G L 3}$ & Highly fractured calcareous rocks & 24 & 100 & 25 & 775 \\
\hline $\mathbf{G L 4}$ & $\begin{array}{c}\text { Medium fractured limestones and } \\
\text { dolomitic limestones }\end{array}$ & 24 & 200 & 35 & 1120 \\
\hline
\end{tabular}

\subsection{Analysis of the Building Typology}

As the railway line crosses the entire municipality, detailed investigations and buildingby-building numerical modelling would be too onerous in terms of time and cost. For this reason, a preliminary study has been carried out to identify the recurrent structural and typological characteristics of the above-surface structures in the investigated area and, consequently, define a representative "index" building $[27,28]$.

To this scope, a specific procedure (Figure 1) was used to extract and elaborate the data from different available sources, managed and integrated into a GIS environment, 
using the QGis open source software [29]. A preliminary analysis was conducted using the ISTAT georeferenced dataset [30]. Data regarding the number of buildings, structural typology (masonry, reinforced concrete, other materials), class of construction age ( $\leq 1919$, 1919-1945, 1946-1960, 1961-1970, 1971-1980, 1981-1990, 1991-2000, 2001-2005, $\geq 2005$ ), and number of floors $(1,2,3, \geq 4)$ were considered for each census section along the railway route. The number of buildings present in the area is 420 of which more than $80 \%$ had a R.C. structure, about 40\% were built between 1971 and 1982, and around 35\% had two-storeys.

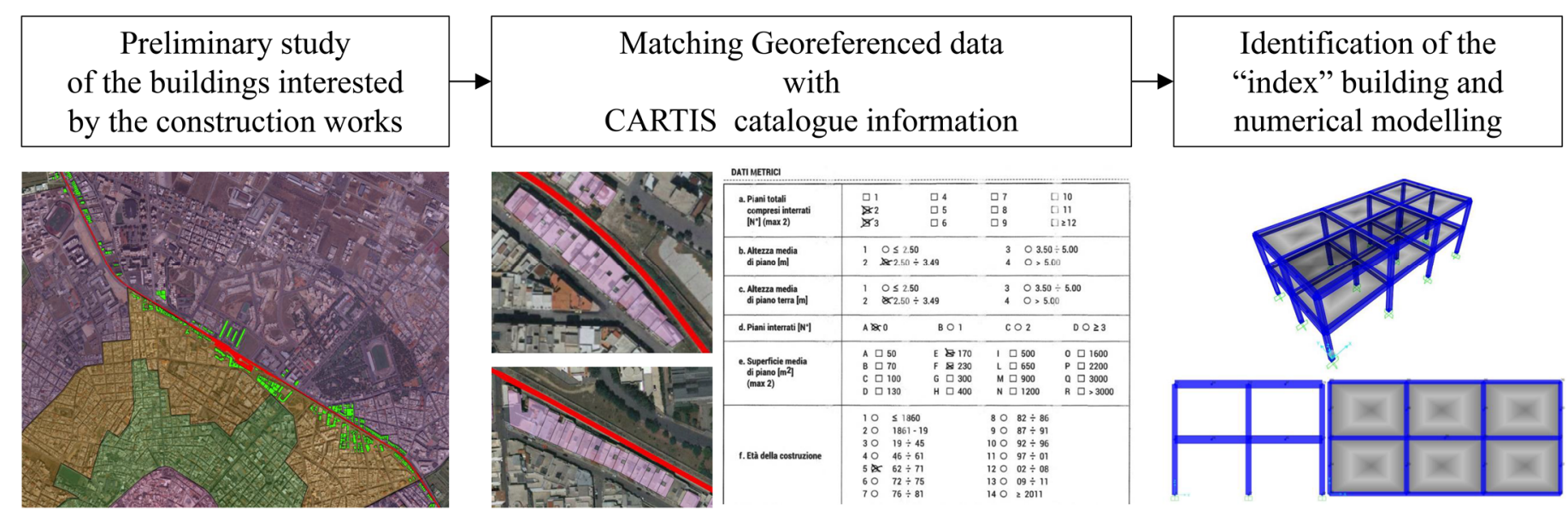

Figure 1. Steps followed for the identification of the "index" building.

A more detailed study was, then, carried out combining different datasets, i.e., the ReLUIS CARTIS catalogue [31], the Cadastral georeferenced vector maps, the Digital Terrain Model (DTM), and the Digital Surface Model (DSM). The CARTIS catalogue, developed within the framework of the ReLUIS project coordinated by the Italian Civil Protection, contains information about homogeneous urban sectors and relative structural and typological classes of existing residential buildings. The Cadastral maps together with the DTM and DSM models allow to obtain georeferenced data about the surface area and the height of each individual building. These figures can be matched with the CARTIS geometrical data to assign the typological class and the pertinent structural information to each structure.

For the specific case study, the railway line marks the borders between two different homogeneous urban sectors: the urban compartment 3 , on the south side of the railway track with a variable width ranging between 85 and $335 \mathrm{~m}$, and the sector 4, which occupies the northern side of the railway extending for about $1.6 \mathrm{~km}$. According to the CARTIS catalogue, three different R.C. structural classes can be identified in the first sector, namely, CAR1, CAR2, and CAR3, and two R.C. structural classes can be defined within the urban compartment 4, i.e., CAR1 and CAR2. By matching the data regarding the surface area and height, almost all buildings closest to the railway fall under the CAR1 class of the urban sector 3 and the CAR1 class of the urban compartment 4, which have similar structural and typological characteristics. Indeed, more than $70 \%$ of the buildings in the area under study have a floor surface between 70 and $200 \mathrm{~m}^{2}$ and almost all of them are characterized by regularity in plan and elevation, with a prevalent rectangular shape and an average inter-storey height between $2.5 \mathrm{~m}$ and $3.5 \mathrm{~m}$.

Therefore, the "index" building was identified, coherently with the relevant information previously derived by the different datasets integrated with the CARTIS typological classes, as follows: R.C. structure, class of construction age 1971-1982, average floor area equal to $135 \mathrm{~m}^{2}$ with usual dimensions of $16.8 \mathrm{~m}$ by $8 \mathrm{~m}$, average inter-storey height equal to $3 \mathrm{~m}$, masonry infill panels with $30 \mathrm{~cm}$ thickness, ribbed slab with R.C. joists and $25 \mathrm{~cm}$ high hollow clay blocks completed by a $5 \mathrm{~cm}$ thick R.C. plate. 


\section{Numerical Simulation of the Rock Excavation Process}

\subsection{Description of the FE Model}

The aim of the geotechnical modelling is to investigate the effects of the excavation processes on the surrounding structures and to identify the most appropriate mitigation strategy to reduce the construction-induced vibrations. As the railway line is characterized by a long longitudinal extension, different excavation techniques can be potentially adopted along its route, depending on the strength of the in-situ material. Indeed, granular soils can be dug out with simple excavators, poor rocks might be excavated by using either simple excavators or pneumatic hammers (depending on the RQD value), while limestones and dolomitic limestones are difficult to be removed through traditional methods. In the specific case study, the worst scenario in terms of construction-induced vibrations, represented by an excavation in the presence of fair rocks (GL4) with high RQD value, was considered for the detailed numerical investigation.

The simulations were carried out through the 2D finite element software PLAXIS 2D [32]. The model adopted in the FE analyses is $200 \mathrm{~m}$ wide and $30 \mathrm{~m}$ high, discretized into 24,730, 15-noded triangular elements under plane strain conditions (Figure 2), consistently with the long longitudinal extension of the investigated railway line. The width of the model was chosen large enough to prevent spurious wave reflections along the boundaries. The coarseness of the FE mesh was refined in order to obtain a distance between two consecutive nodes smaller than approximately one-eighth of the wavelength associated with the maximum frequency of the input wave, i.e., $h_{\min }=V_{\mathrm{s}} /\left(8 \cdot f_{\max }\right)$.

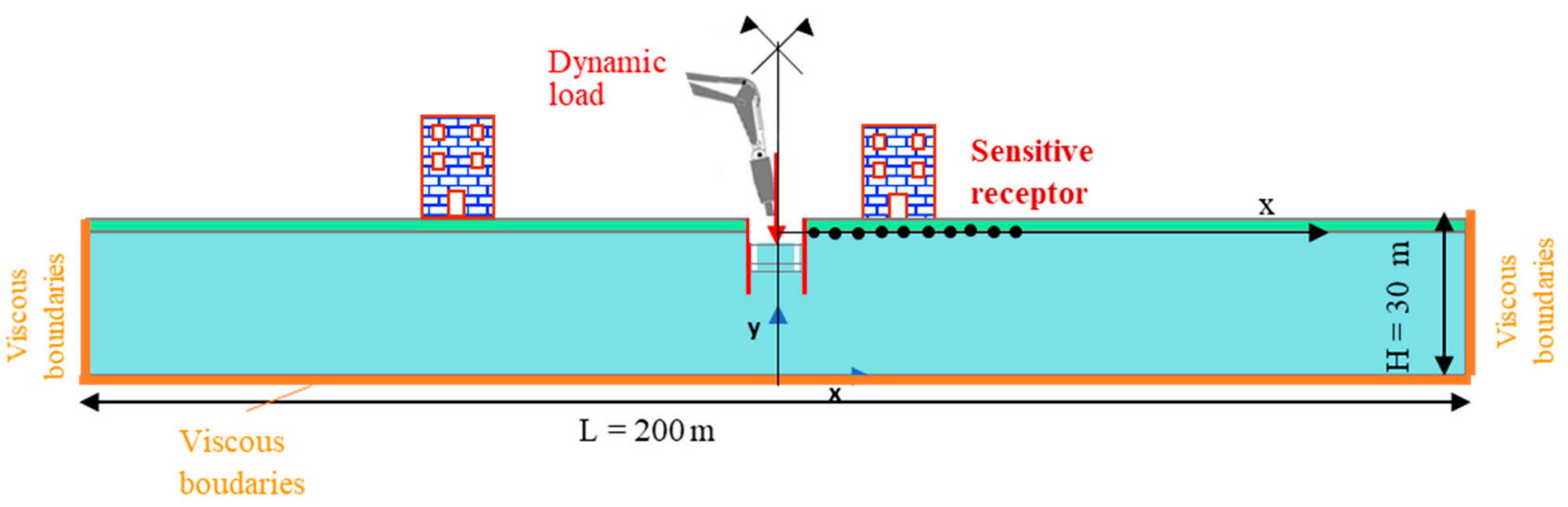

Figure 2. Numerical model of the rock excavation process.

The local soil profile consists of a first layer of filling material (GL1) with a thickness of $2 \mathrm{~m}$, overlaying the dolomitic limestone layer (GL4) extending down to depth. Both strata were modeled using the linear elastic-perfectly plastic Mohr-Coulomb (MC) model, assuming a non-associated flow rule (i.e., $\psi=0^{\circ}$ ). The $\mathrm{MC}$ model parameters, reported in Table 2, are consistent with the mechanical properties obtained from the in-situ investigations. The Poisson's ratio was estimated through the elastic equation $K_{0} /\left(1+K_{0}\right)$, i.e., as a function of the coefficient of earth pressure at rest, $K_{0}$, which depends on the frictional angle according to the relationship $K_{0}=1-\sin \varphi^{\prime}$ [33]. Under the assumption of isotropic linear elasticity, the Young modulus $E^{\prime}$ was determined as a function of the shear stiffness $G$, this latter related to the shear wave velocity vs. and the unit weight $\gamma$ of each material.

The dissipative capacity of each material was implemented through Rayleigh viscous damping [34], whose parameters $\alpha_{\mathrm{R}}$ and $\beta_{\mathrm{R}}$ can be calculated as follows [35]:

$$
\left\{\begin{array}{c}
\alpha_{R} \\
\beta_{R}
\end{array}\right\}=\frac{2 D^{*}}{\omega_{m}+\omega_{n}}\left\{\begin{array}{c}
\omega_{m} \omega_{n} \\
1
\end{array}\right\}
$$

where $D^{*}$ is the target damping and $\omega_{m}$ and $\omega_{n}$ are the two angular frequencies defining the interval over which the viscous damping is equal to or lower than $D^{*}$. Thus, assuming $\omega_{m}$ 
equal to $0.63 \mathrm{rad} / \mathrm{s}$ and $\omega_{n}$ equal to $12.57 \mathrm{rad} / \mathrm{s}$ according to [36], the Rayleigh coefficients are those reported in Table 2.

Table 2. Material parameters adopted in the FE simulations of the excavation.

\begin{tabular}{cccccccccccc}
\hline & $\gamma$ & $\boldsymbol{C}^{\prime}$ & $\boldsymbol{\Phi}^{\prime}$ & $\boldsymbol{K}_{\mathbf{0}}$ & $\boldsymbol{v}$ & $V_{\mathbf{s}}$ & $\boldsymbol{G}$ & $\boldsymbol{E}^{\prime}$ & $D^{*}$ & $\alpha_{\mathbf{R}}$ & $\beta_{\mathbf{R}}$ \\
\hline $\mathbf{k N} / \mathbf{m}^{\mathbf{3}}$ & $\mathbf{k P a}$ & $\circ$ & - & - & $\mathbf{m} / \mathbf{s}$ & $\mathbf{M P a}$ & $\mathbf{M P a}$ & $\mathbf{\%}$ & - \\
\hline $\mathbf{G L 4}$ & 18 & 0 & 24 & 0.53 & 0.35 & 437 & $3.5 \times 10^{2}$ & $9.46 \times 10^{2}$ & 2 & $2.39 \times 10^{-2}$ & $3.03 \times 10^{-3}$ \\
\hline $\begin{array}{c}\text { Weakened } \\
\text { GL4 }\end{array}$ & 24 & 200 & 35 & 0.43 & 0.3 & 1120 & $3.07 \times 10^{3}$ & $7.98 \times 10^{3}$ & 5 & $5.984 \times 10^{-2}$ & $7.579 \times 10^{-3}$ \\
\hline
\end{tabular}

A typical cross-section of the excavated trench, $8 \mathrm{~m}$ wide and $9 \mathrm{~m}$ deep, was analyzed as shown in Figure 3. The excavation is supported by a provisional $14 \mathrm{~m}$ deep wall, consisting in a set of contiguous micro-piles reinforced with HEB steel beams, installed to avoid instability problems related to the shallower soil layer (GL1). The retaining structure was modeled with elastic plate elements, characterized by a unit weight of $22 \mathrm{kN} / \mathrm{m}^{3}$, normal stiffness $E A$ equal to $2.28 \times 10^{7} \mathrm{kN} / \mathrm{m}$, and flexural rigidity $E I$ equal to $1.59 \times 10^{6} \mathrm{kNm}^{2} / \mathrm{m}$. Interface elements were used around the wall with a reduction strength factor of 1.0. The presence of water was not considered in the simulations, as indicated by the in-situ investigations.

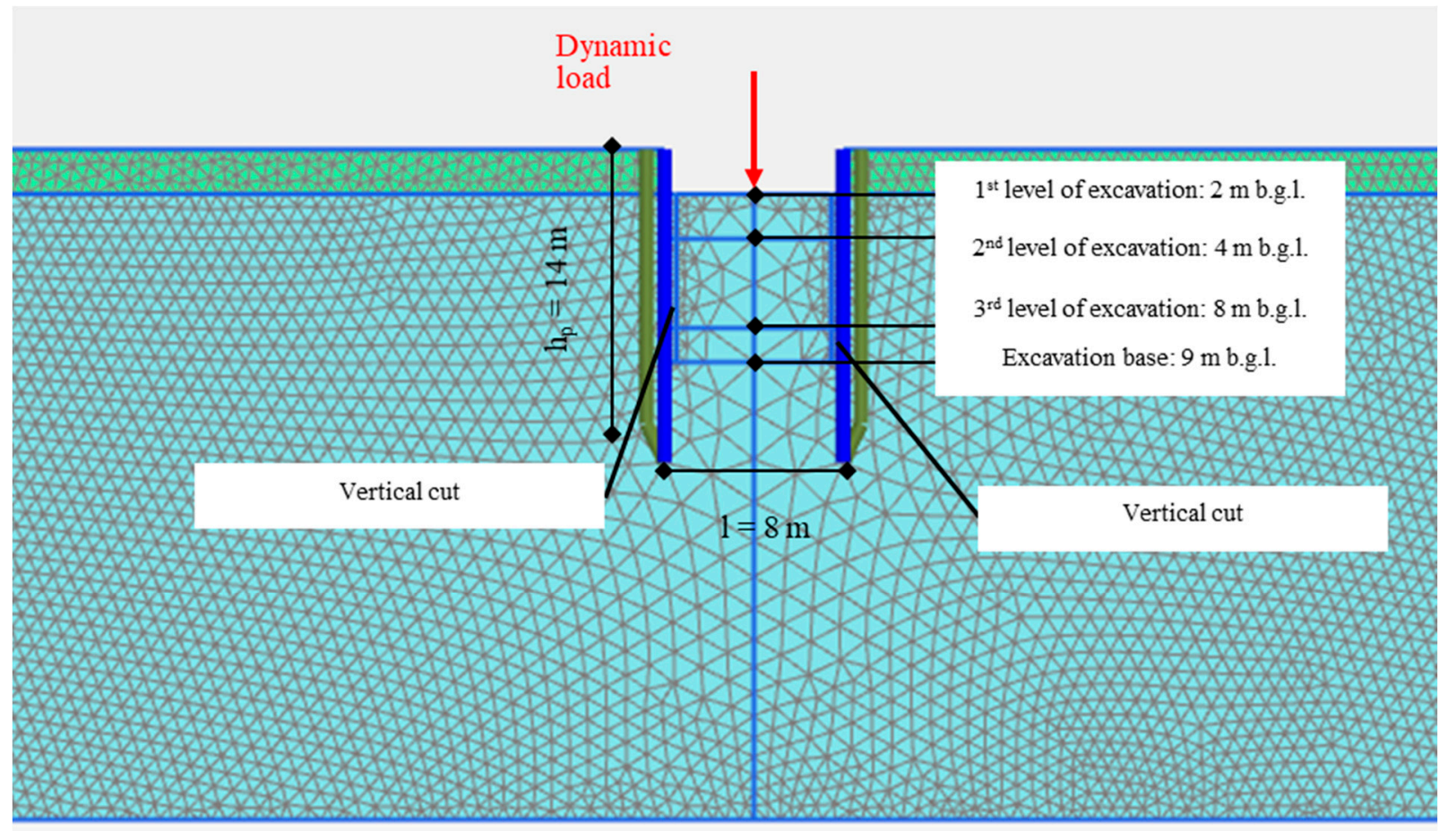

Figure 3. Details of the geotechnical numerical model.

After the initialization of the geostatic stress state (performed through a standard $K_{0}$-procedure), the installation of the diaphragm walls was simulated, followed by a first excavation phase during which the backfill material inside the trench was removed (first excavation level). Starting from a depth of $2 \mathrm{~m}$ below ground level (b.g.l.), three consecutive phases were simulated to progressively reach $4 \mathrm{~m}$ (second excavation level), $8 \mathrm{~m}$ (third excavation level), and $9 \mathrm{~m}$ b.g.l. (i.e., the excavation base). Each excavation stage in the 
rock mass was numerically simulated by means of two successive phases (Figure 3): a first dynamic phase during which an impulsive force was applied at the trench base to simulate the action of the breaker hammer (representing a source of vibrations for the system); a second phase consisting in removing the spoil material down to the desired depth. In an ideal scenario, as the one investigated in the paper, the application of the dynamic load in the center of the excavation section is deemed correct, assuming that the R.C. buildings are located on both sides of the trench. Otherwise, higher excitations at the base of the "index" building would have been obtained by applying the dynamic load closer to one side of the trench, depending on the actual position of the above-surface structure. Standard boundary conditions were adopted during the static stages, while viscous boundaries [37] were applied along the vertical sides and at the bottom of the FE model during the dynamic phases of the geotechnical analysis (see Figure 2).

With the aim of quantifying the potential impact of different solutions, three different scenarios were considered to simulate the excavation of the GL4 layer, as described in the following:

- Scenario 1-“Traditional excavation technique": a dynamic load simulating the impulsive force of a hydraulic hammer was applied as a periodic time history, with amplitude and frequency defined as a function of the hammer characteristics and rock mass strength.

- Scenario 2-“Excavation with vertical cut": a $3 \mathrm{~cm}$ thick vertical cut, obtained in the real construction works through a chain saw machine, was modeled by removing the rock elements close to the retaining structure up to the design depth. This was followed by the application of the dynamic load which simulates the hydraulic hammer action, as in Scenario 1. The vertical cut allows to create a material discontinuity in the construction area, thus reducing the intensity of the vibrations propagating in the medium.

- Scenario 3-“Excavation with crushing treatment": in addition to the vertical cut, a crushing treatment with a carbon dioxide cracker was simulated by modifying the dynamic properties of the rock mass to be excavated. This was taken into account by reducing its shear wave velocity to $40 \%$ of the intact rock value and increasing its damping ratio (see the properties of the Weakened GL4 layer in Table 2). The rock weakening treatment was followed by the application of a smaller hydraulic hammer action, as explained in the next section.

\subsection{Evaluation of the Impulsive Force}

The impact force of the breaker hammer was modeled as a point dynamic load applied in the center of the trench base (Figure 3). This time dependent load was defined as a rectangular impulsive signal of amplitude $F_{\max }$, cyclically repeated with the hammer peak frequency. The amplitude was evaluated considering the hammer type, identified as a function of the uniaxial compressive strength of the rock and the target daily excavation progress. Fixing the fall height $h$ and the elastic rebound $\eta$, the maximum intensity of the impact force $F_{\max }$ was determined as

$$
F_{\max }=\eta \kappa \frac{E}{h}
$$

where $E$ is the impact energy per hammer blow and $\kappa$ is equal to the period $T$ between two peaks divided by $\Delta T_{\text {pulse }}$. The frequency and impact energy are the function of the hammer type. For the first two scenarios involving the excavation of the intact fair rock, a 11 tons heavy hydraulic hammer, characterized by an energy per hammer blow equal to 25,000 Joule and a frequency of $240 \mathrm{blow} / \mathrm{min}$, was selected. When considering the third scenario, instead, the weakening of the rock mass allows the adoption of a hydraulic hammer with a lower energy per hammer blow. In this case, the selected hammer is characterized by a value of energy per hammer blow equal to 14,120 Joule and a frequency of $270 \mathrm{blow} / \mathrm{min}$. The characteristics of the hammers and the corresponding $F_{\max }$ values 
are summarized in Table 3 for each excavation scenario, while Figure 4 shows the applied time history of the impulsive force.

Table 3. Characteristics of the dynamic force simulating the hammer action.

\begin{tabular}{ccccccccc}
\hline & $E$ & $\kappa$ & $\eta$ & $h$ & Frequency & $\boldsymbol{T}$ & $\Delta T_{\text {pulse }}$ & $F_{\max }$ \\
\hline & $\mathbf{J}$ & - & - & $\mathbf{c m}$ & blow/min & $\mathbf{S}$ & $\mathbf{s}$ & $\mathbf{k N}$ \\
\hline Scenarios 1 and 2 & 25,000 & 10 & 1.40 & 4.0 & 240 & 0.25 & 0.025 & 8750 \\
\hline Scenario 3 & 14,120 & 10 & 1.25 & 3.5 & 270 & 0.22 & 0.022 & 5043 \\
\hline
\end{tabular}

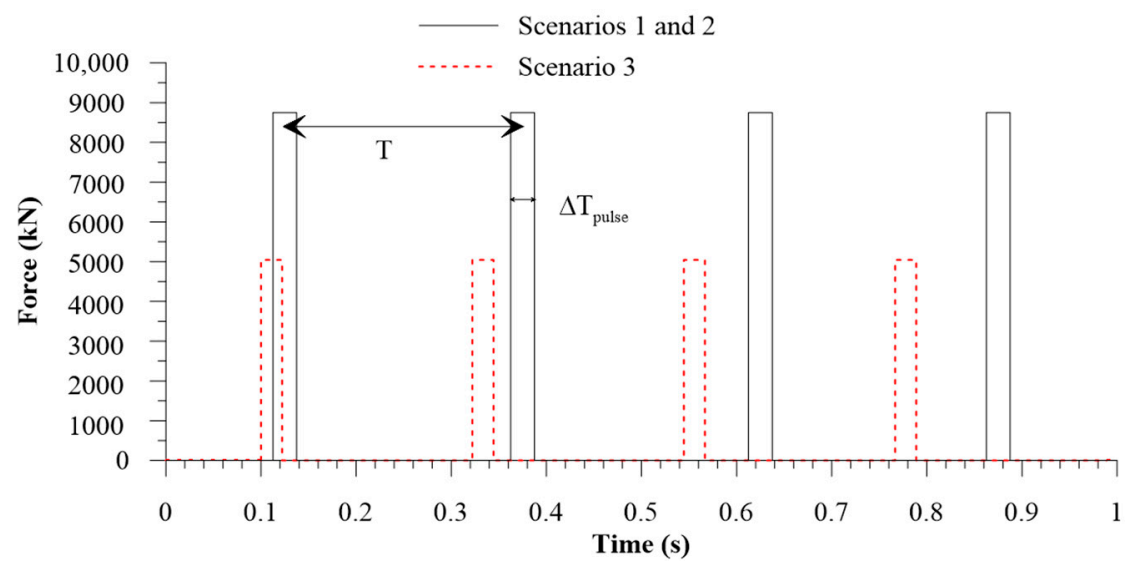

Figure 4. Input signal applied to simulate the action of hammer during the excavation.

\subsection{Numerical Results}

The results of the numerical analyses performed for the first scenario are presented in Figure 5 in terms of vertical and horizontal acceleration time histories obtained at $2 \mathrm{~m}$ b.g.l. during the second excavation phase, for different distances from the applied dynamic load. As the distance from the symmetry axis increases, the peak acceleration values decrease, due to the geometrical dissipation. Moreover, the vertical accelerations are higher than the horizontal ones, indicating that the hammer-induced vibrations are basically related to the propagation of compressional waves. Comparing the acceleration time histories obtained after each level of excavation, it can be observed that the worst situation in terms of construction-induced vibrations occurs at the beginning of the second excavation phase, i.e., when the base is $2 \mathrm{~m}$ below the ground surface. Then, the peak acceleration values reduce as the excavation progresses down. However, the level of vibrations induced by the traditional excavation is high enough to produce damages to the surrounding buildings and nuisance to people, thus requiring the adoption of mitigation measures.

Scenario 1

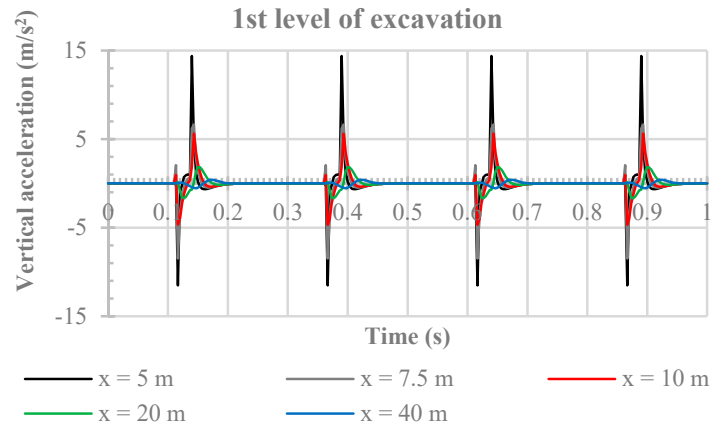

(a)
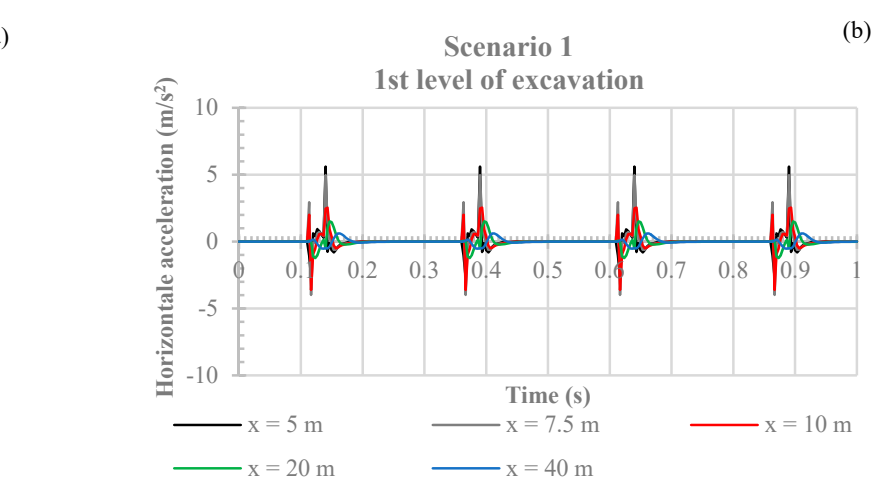

Figure 5. Traditional excavation technique (Scenario 1): (a) vertical and (b) horizontal acceleration time histories obtained at different distances from the symmetry axis during the second excavation stage. 
In Figure 6, the vertical and horizontal acceleration time histories obtained at a distance of $5 \mathrm{~m}$ and $10 \mathrm{~m}$ from the impact force for Scenarios 2 and 3 are compared to those obtained by a traditional excavation method (Scenario 1 ). The presence of the vertical cut (Scenario 2) has a beneficial effect in terms of reduction of the peak vertical acceleration values; this reduction is more significant closer to the vibration source and becomes less pronounced as the distance increases (Figure 6a,c). A drastic decrease of the induced vibration level is obtained in the third scenario, as the maximum amplitude of the vertical accelerations is much smaller than in the other two cases. This is mainly due to the different applied impulsive load, which is characterized by a higher frequency and a lower force amplitude compared to the first and second scenarios (Figure 4). A marginal role is, instead, played by the preliminary fragmentation of the rock mass.

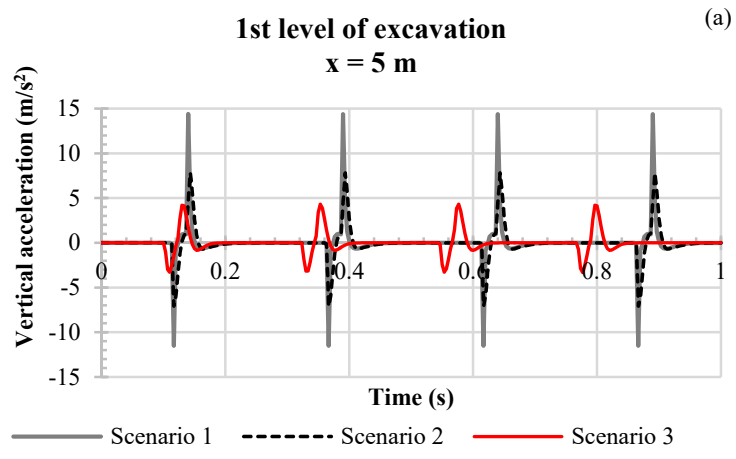

1st level of excavation

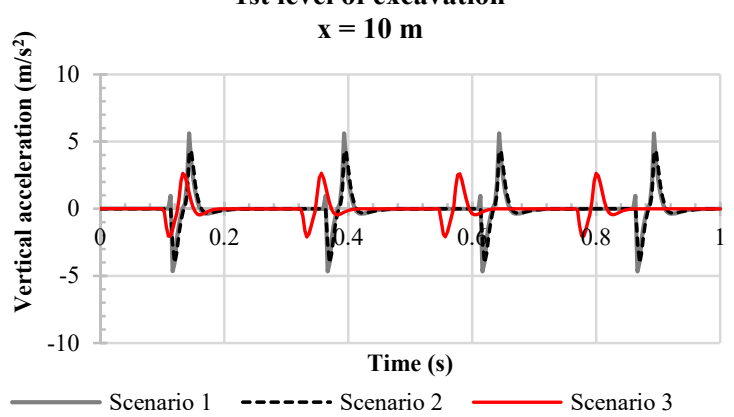

(a)

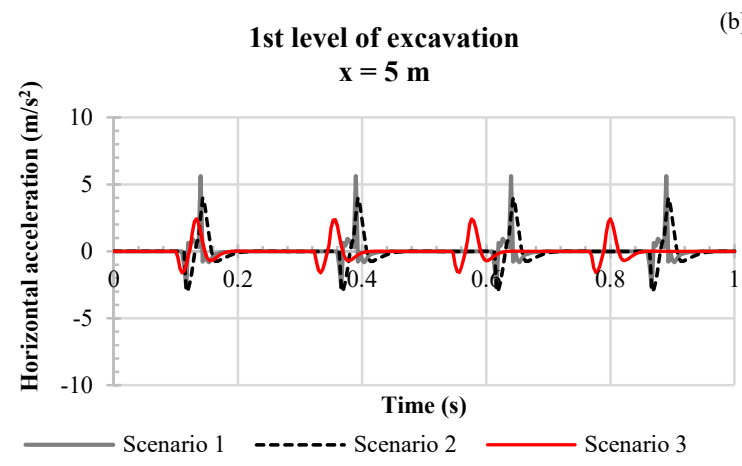

1st level of excavation $\mathbf{x}=\mathbf{1 0} \mathbf{m}$

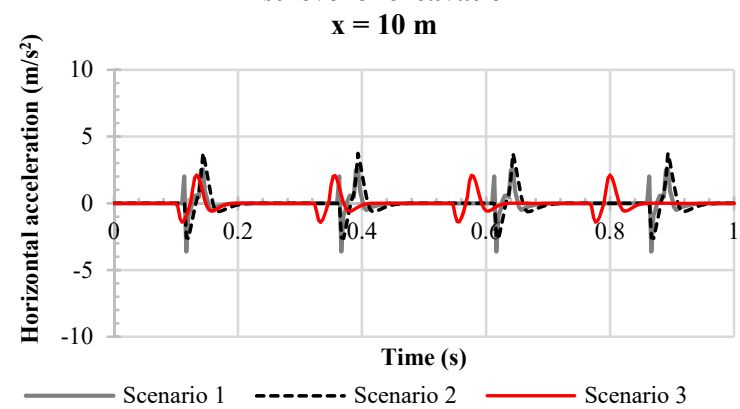

Figure 6. Comparison between different excavation scenarios: vertical and horizontal acceleration time histories obtained at a distance of $(\mathbf{a}, \mathbf{b}) 5 \mathrm{~m}$ and $(\mathbf{c}, \mathbf{d}) 10 \mathrm{~m}$ from the symmetry axis during the second excavation stage.

Figure 7 illustrates the variation of the peak accelerations obtained at $2 \mathrm{~m}$ below ground surface outside the trench with distance from the vibration source considering the three excavation scenarios. In all cases, the decrease of the horizontal acceleration with distance from is less pronounced than that obtained for the vertical component. Moreover, the preliminary vertical cut (Scenario 2) has a significant mitigation effect for distances lower than $10 \mathrm{~m}$; beyond this point, its positive contribution becomes irrelevant. The adoption of a crushing treatment (Scenario 3) has a substantial effect for distances smaller than $17.5 \mathrm{~m}$, while the dynamic response of the system is equal to that predicted by the traditional excavation simulation for higher distances from the source.

Vibration-induced damage thresholds are usually expressed in terms of peak component particle velocity, as the $p c p v$ has been found to be better correlated with real data of structural damage [2]. Figure 8 shows the decrease of the peak particle velocity of the vertical component of motion with the scaled distance from the vibration source, representing the attenuation law of the vibration level. The scaled distance was evaluated through the relationship $100 D / E^{0.5}$, where $E$ is the impact energy of the hammer and $D$ is the distance from the source. The $p c p v$ refers to the maximum value associated to a point in the ground at $2 \mathrm{~m}$ depth below the ground surface, where building foundations are located. The 
numerical predictions reveal that, as expected, a larger attenuation of the ground vibration might be obtained when the rock is preliminary disaggregated before the mechanical excavation. Indeed, the mitigation measure consisting in the fragmentation of the rock mass with non-explosive systems provides a significant decrease of the peak particle velocity, sufficiently below the threshold value for standard buildings [22]. It should be noted that the obtained $p c p v$ vs. scaled distance curves are consistent with the experimental data and numerical simulations of pile driving, blasting, and rock excavation with hydraulic hammers [1,2,38-41]. Since in-situ measurements were unavailable for the specific case study, other forms of validation of the presented numerical results have not been possible.
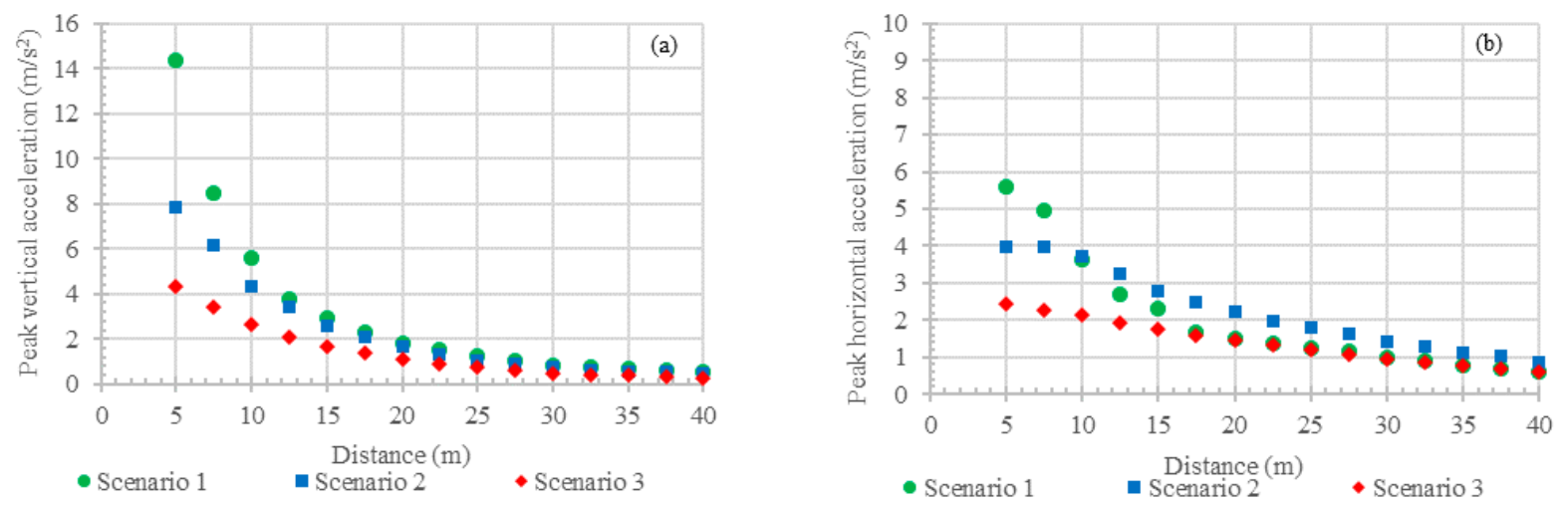

Figure 7. Comparison between different excavation scenarios: variation with distance of (a) peak vertical acceleration and (b) peak horizontal acceleration.

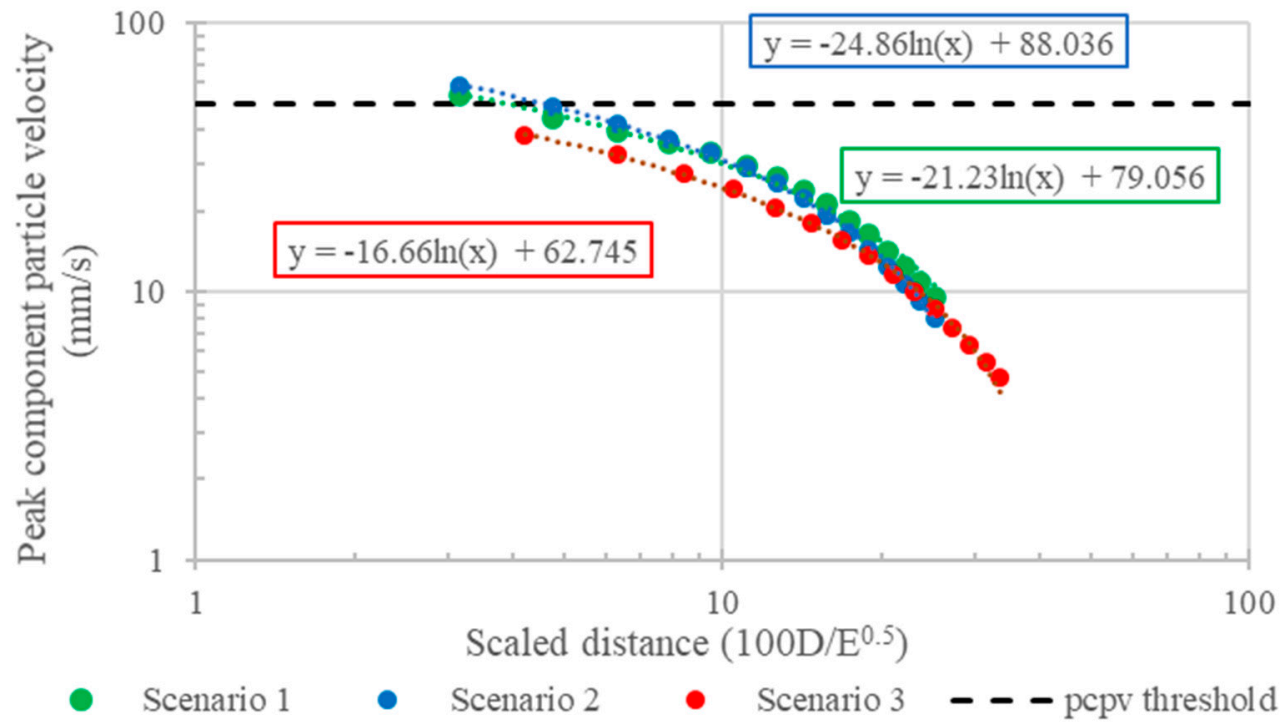

Figure 8. Comparison between different excavation scenarios: variation with scaled distance of the peak component particle velocity.

\section{Modelling and Structural Analysis}

\subsection{Structural Model and FE Analyses}

The "index" building identified in Section 2.2 was modeled through the 3D FE software SAP2000 [42]. The aim of the structural modelling and analysis is to evaluate the vibrations effects induced by the dynamic force relative to the different geotechnical scenarios on the "index" building and to verify the best mitigation solution to ensure the well-being of its occupiers.

The verification of the vibration effects was performed, at first, comparing the two horizontal and the vertical components of the peak particle velocity of the center of the 
mass of the upper slab with the thresholds given by the Italian standards [22]. Then, considering the deformability of the floor system [43], a further verification was carried out by comparing the maximum displacements induced in the center of the mass of each floor with the limit values derived by the Italian building code [21].

With reference to the structural modelling (Figure 9), the geometrical and typological characteristics of the building are those extrapolated according to the abovementioned procedure. The mechanical parameters were considered coherently with the age of construction. In particular, the concrete strength $f_{\mathrm{cm}}$ was assumed equal to $25 \mathrm{~N} / \mathrm{mm}^{2}$, while the yielding steel strength was selected equal to $f_{\mathrm{yk}}=450 \mathrm{~N} / \mathrm{mm}^{2}$. Then, a simulated design was performed to calculate the dimensions of the structural elements. Beam and columns were modeled as frame elements, using fixed restraints at the base of the columns; the horizontal slabs were considered as rigid using internal constraints, permanent loads (G1 and G2) and live loads (Q) were defined and masonry infill was considered as a load on the beam elements.

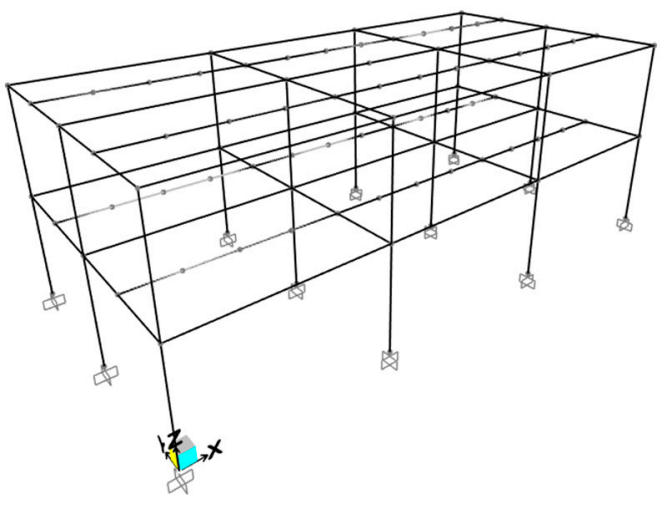

(a)

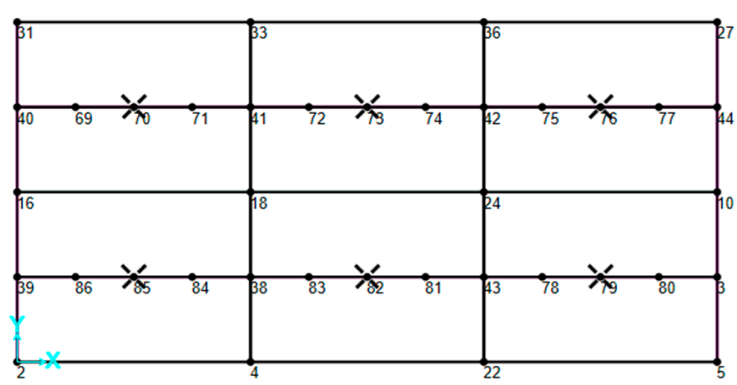

(b)

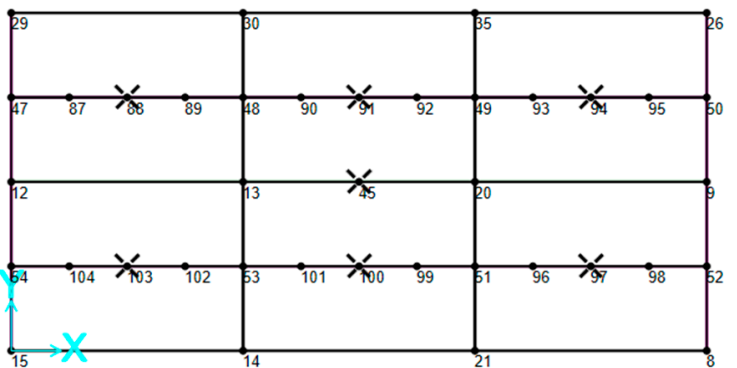

(c)

Figure 9. (a) Numerical model of the "index" building (b) control points on the first storey (c) control points on the upper slab.

Different nonlinear dynamic analyses were carried out adopting the horizontal and vertical acceleration time histories obtained at the distance of $10 \mathrm{~m}$ from the axis of the geotechnical model, relative to Scenarios 2 and 3. For both cases, the peak values of the accelerations time histories are small enough not to induce plastic deformations in the building. Therefore, it is reasonable to assume an elastic behavior of the structural model. The conducted nonlinear dynamic analyses are the following:

- Two FE simulations performed applying the two horizontal component of the acceleration time history (along the directions $\mathrm{x}$ and $\mathrm{y}$ ) and the vertical component of the acceleration time history in the vertical direction (i.e., z). For each analysis, the velocity time history in the center of the mass of the upper slab coincident with node 45 was monitored (Figure 9). The output correspondent to Scenarios 2 and 3 was considered. 
The $p c p v_{0}$ of the control point was compared with the threshold $\left(p c p v_{\lim }\right)$ fixed by the technical standard to $0.05 \mathrm{~m} / \mathrm{s}$ [22], verifying that

$$
p c p v_{0}<p c p v_{\text {lim }}
$$

- Two FE analyses conducted using as input motion at the base of the building the vertical time histories recorded at a distance of $10 \mathrm{~m}$ for the Scenarios 2 and 3. The control points were assumed in the center of the mass of each floor (i.e., nodes $70,73,76,76,82$, 85 for the first storey and nodes $86,91,94,98,100,103$ for the second storey), as shown in Figure 9. The monitored output was the vertical displacement time history of the control points. The maximum displacement of each node $\delta_{0}$ was compared with the threshold, $\delta_{\text {lim }}$, equal to $30 \mathrm{~mm}$ [21], verifying that

$$
\delta_{0}<\delta_{\lim }
$$

\subsection{Results and Assessment}

Figure 10 shows the comparison between the horizontal and vertical velocities of the control point 45 induced by the ground vibrations obtained from the geotechnical analyses of Scenarios 2 and 3. Scenario 3 induces lower velocities than Scenario 2, indicating that the adoption of the crushing treatment allows a significant reduction in term of vibration effects with respect to case of the excavation with a lateral cut. Moreover, the velocity induced in the vertical direction is higher than that in the two horizontal directions. Indeed, the values of the $p c p v_{0}$ in the $\mathrm{x}$ and $\mathrm{y}$ directions are lower than the $p c p v_{\lim }$ specified by the technical standard for both scenarios (Figure 10), while the $p c p v_{0}$ of node 45 in the vertical direction related to Scenario 2 exceeds the limit value required by the code prescriptions (Table 4). Thus, Scenario 3 allows a greater mitigation of the vibrations induced on the structure in terms of $p c p v$. It is also worth to highlight that the adoption of the excavation method described by Scenario 3 leads to a significant reduction of the $p c p v_{0}$ in the $\mathrm{x}$ and y directions, respectively equal to $48 \%$ and $47 \%$, while a lower reduction of the $p c p v_{0}$ in vertical direction equal to $27 \%$ can be observed. Nevertheless, the preliminary crushing treatment allows to obtain a $p c p v_{0}$ value which respects the technical requirements.

Table 4. Values of peak component particle velocity in the vertical direction ( $\left.p c p v_{0}\right)$ obtained in node 45 and comparison with the peak component particle velocity in the limit ( $\left.p c p v_{\text {lim }}\right)$.

\begin{tabular}{cccccc}
\hline \multicolumn{2}{c}{ Horizontal x $p c p v$} & \multicolumn{2}{c}{ Horizontal y $p c p v$} & \multicolumn{2}{c}{ Vertical pcpv } \\
\hline Scenario 2 & Scenario 3 & Scenario 2 & Scenario 3 & Scenario 2 & Scenario 3 \\
\hline $\mathbf{m} / \mathbf{s}$ & $\mathbf{m} / \mathbf{s}$ & $\mathbf{m} / \mathbf{s}$ & $\mathbf{~ m} / \mathbf{s}$ & $\mathbf{m} / \mathbf{s}$ & $\mathbf{m} / \mathbf{s}$ \\
\hline $0.0341<0.05$ & $0.0167<0.05$ & $0.0335<0.05$ & $0.0164<0.05$ & $0.1695>0.05$ & $0.046<0.05$ \\
\hline
\end{tabular}

In regards to the structural response in terms of vertical displacements $\delta$, Figure 11 presents the comparison between the displacement time histories induced by the Scenarios 2 and 3 in the different control points. Both excavation techniques induce higher displacements in the second storey than those calculated for the first storey. Scenario 3 causes lower displacements than Scenario 2 in all the control points. In particular, the use of a crushing treatment allows a substantial reduction of the maximum vertical displacements, ranging from $51 \%$ in node 76 on the first storey to $62 \%$ in node 92 on the second storey (Table 5). 


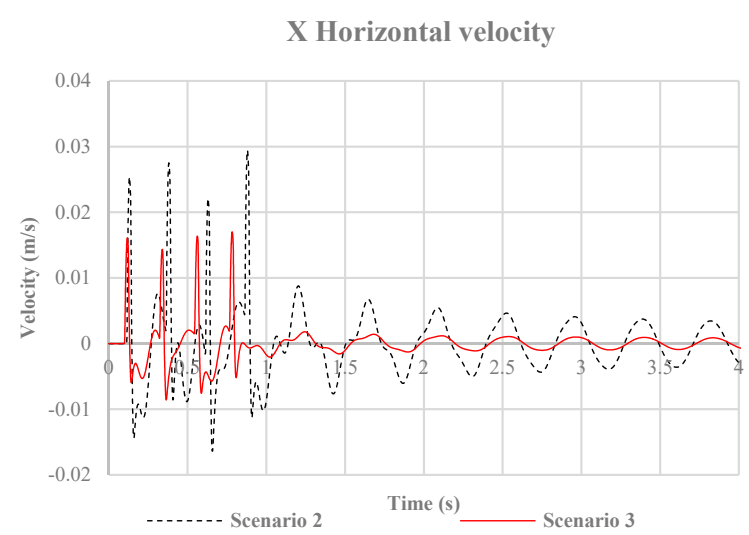

(a)

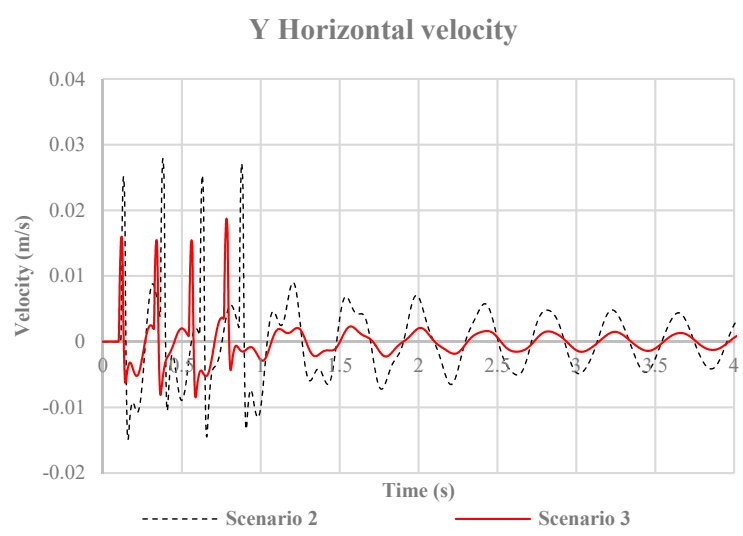

(b)

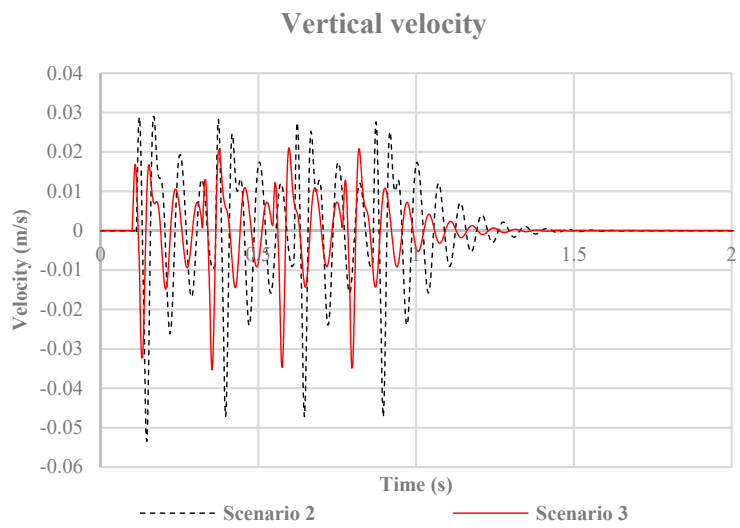

(c)

Figure 10. Comparison between the two excavation techniques in terms of (a) horizontal velocity in the $x$ direction (b) horizontal velocity in the $y$ direction (c) vertical velocity of the control point.
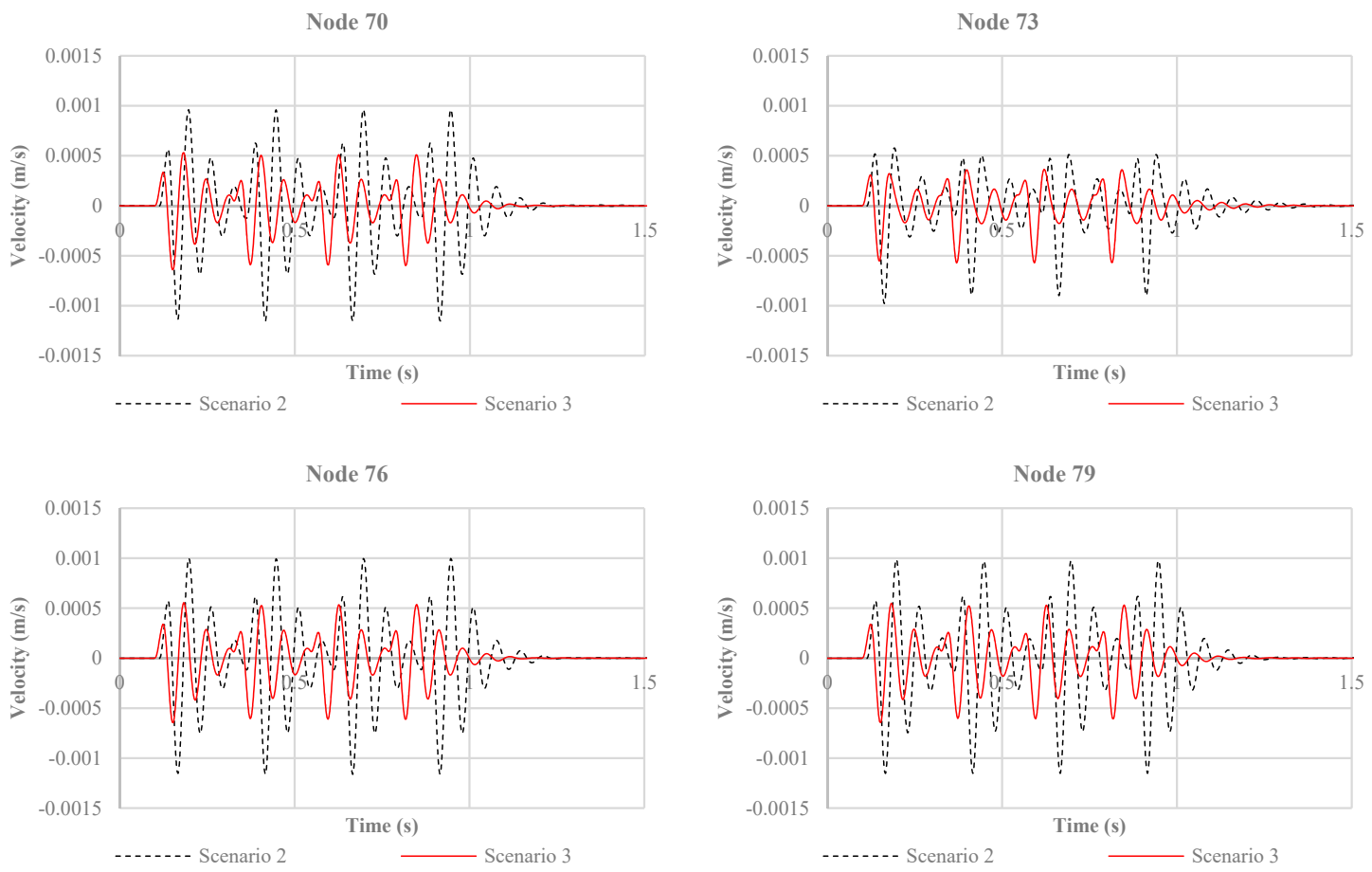

Figure 11. Cont. 

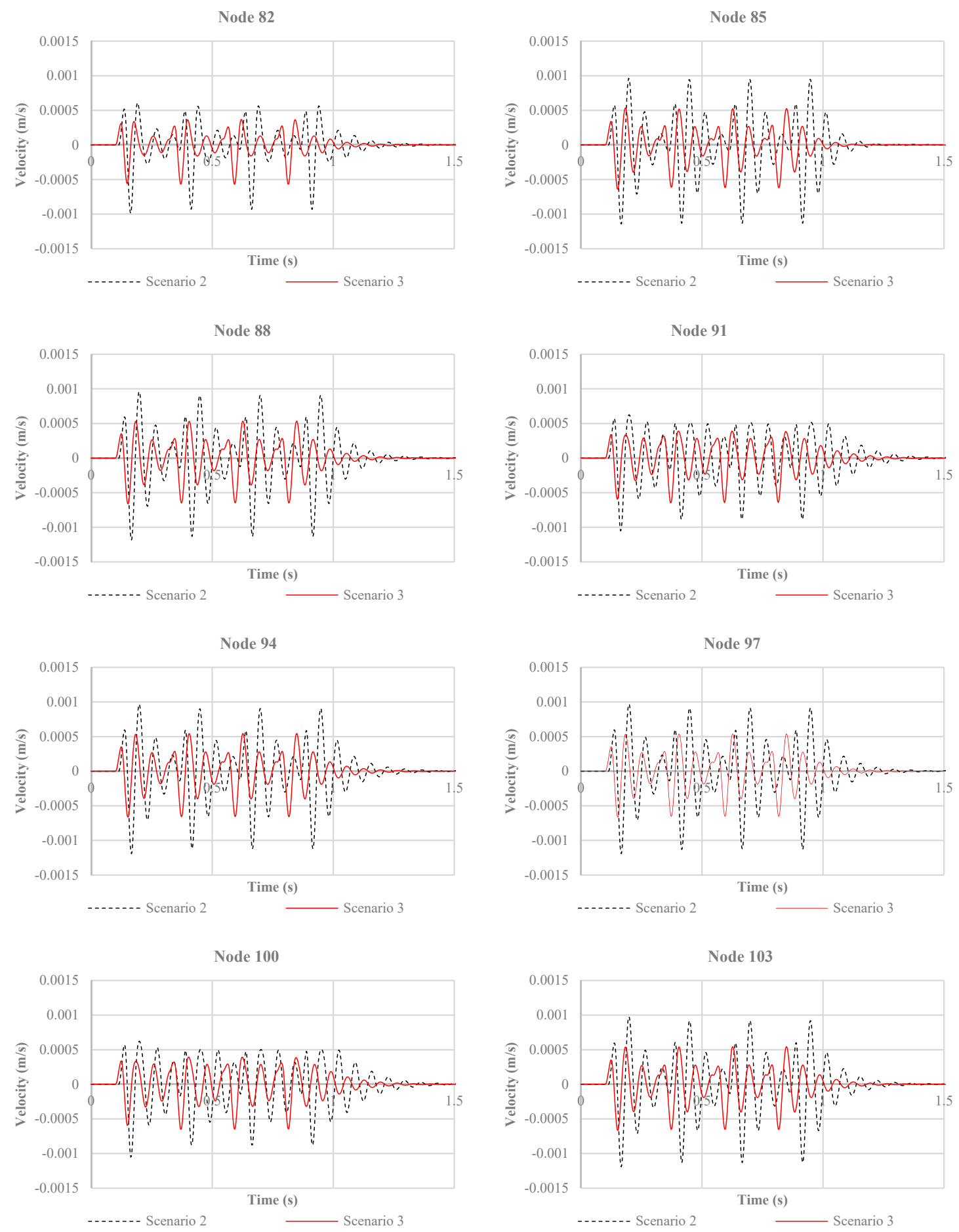

Figure 11. Comparison between the two excavation techniques in terms of vertical displacement time histories of the control points. 
Table 5. Values of $\delta_{0}$ obtained in the control points and comparison with $\delta_{\lim }$.

\begin{tabular}{cccc}
\hline Node & $\begin{array}{c}\text { Displacement } \\
\text { with Lateral Cut } \\
{[\mathbf{m}]}\end{array}$ & $\begin{array}{c}\text { Displacement } \\
\text { with Crushing Treatment } \\
{[\mathbf{m}]}\end{array}$ & $\begin{array}{c}\text { Reduction of } \\
\text { Vibration Effect } \\
{[\%]}\end{array}$ \\
\hline 70 & $0.001151<0.03$ & $0.000638<0.03$ & 55 \\
73 & $0.000976<0.03$ & $0.000571<0.03$ & 59 \\
76 & $0.001162<0.03$ & $0.000643<0.03$ & 55 \\
79 & $0.001153<0.03$ & $0.000642<0.03$ & 56 \\
82 & $0.000986<0.03$ & $0.000569<0.03$ & 58 \\
85 & $0.001142<0.03$ & $0.000637<0.03$ & 56 \\
88 & $0.001183<0.03$ & $0.000661<0.03$ & 56 \\
91 & $0.001049<0.03$ & $0.000644<0.03$ & 61 \\
94 & $0.001187<0.03$ & $0.000663<0.03$ & 56 \\
97 & $0.001187<0.03$ & $0.000663<0.03$ & 56 \\
100 & $0.001048<0.03$ & $0.000649<0.03$ & 62 \\
103 & $0.001189<0.03$ & $0.000664<0.03$ & 56 \\
\hline
\end{tabular}

\section{Conclusions}

The paper presents a numerical study on the influence of construction-induced vibrations on nearby R.C. buildings. The investigations refer to the case study of the construction works carried out to bury a railway line crossing an urban area in the south of Italy. The excavation works involved dolomitic rocks, characterized by a high resistance to excavation and inducing important vibrations on the surrounding environment. The analysis was performed adopting an uncoupled numerical approach, consisting in separately simulating the dynamic response of the geotechnical system and the above-surface structure, through 2D and 3D FE models, respectively.

Three different scenarios of excavation works were simulated through the 2D geotechnical modelling in order to identify the less impacting excavation technique in terms of vibrations induced on the ground surface, where sensitive receptors (i.e., buildings) are located, and to suggest the most suitable mitigation strategy to reduce these vibrations. The considered rock excavation scenarios involve a traditional excavation technique (Scenario 1), the execution of a preliminary vertical cut followed by the application of the breaker hammer action (Scenario 2) and the use of a hydraulic drill on a pre-cut rock mass, preceded by a crushing treatment of the intact rocks (Scenario 3). For each scenario, the action of the hydraulic drill was simulated through a dynamic force applied at the center of the trench base, whose intensity and frequency was selected as a function of the resistance of the rock mass to be excavated. The elasto-plastic Mohr-Coulomb model was adopted to describe the mechanical behavior of the rock, whose physical and strength parameters were determined from available in-situ data. The results of the geotechnical simulations were used as an input for the structural analyses.

The 3D structural modelling was performed with reference to the characteristics of an "index" building, identified through the procedure proposed by [27] and representative of the most recurrent structural typology in the investigated urban area. A R.C. building, defined as described in Section 2.2, was selected as "index" building.

The geotechnical simulations highlight that the peak acceleration values decrease as the distance from the source increases, due to geometrical dissipation into the rock deposit. Although the dynamic force due to the hydraulic hammer causes the propagation of both compressional and shear waves, the most impacting ones are the compressional waves. The level of vibrations induced by a traditional excavation technique is higher than the one generated during the excavation performed with both the preliminary vertical cut and the crushing treatment. Operating vertical cuts in the rock mass before the excavation reveals to be a good measure for reducing the intensity of the vertical accelerations, as they create a discontinuity in the wave propagation process. However, the beneficial effect in terms of reduction of peak vertical acceleration is more pronounced closer to the vibration source and reduces as the distance increases. The best mitigation effect is 
obtained through the preliminary crushing treatment, which allows the adoption of a less powerful hydraulic hammer due to the smaller resistance to excavation of the fragmented rock mass. This positive contribution in the reduction of the vibrations is confirmed by the structural response of the "index" building. Indeed, the comparison of the peak component particle velocity $p c p v_{0}$ in the vertical direction with the limit, $p c p v_{\text {lim }}$, provided by technical standards highlights that the simple operation of a vertical cut is not sufficient to mitigate the impact of the vibrations on the structure, while the preliminary fragmentation treatment allows to more effectively reduce the vertical velocities recorded in the building.

In conclusion, the numerical investigations reveal that the crushing treatment of the intact rock that operated before the use of the hydraulic drill on a pre-cut rock mass (Scenario 3) represents a successful measure to mitigate the impact of the vibrations induced by construction works on the surrounding buildings.

Author Contributions: Conceptualization and methodology G.E., D.R., and G.U.; investigation and analysis V.L. and A.d.L.; data curation V.L. and A.d.L.; writing-original draft preparation V.L. and A.d.L.; writing-review and editing, V.L., A.d.L., G.E., D.R., and G.U.; supervision G.E., D.R., and G.U. All authors have read and agreed to the published version of the manuscript.

Funding: The presented research has been partially developed within the framework of the ReLUISDPC 2019-2021 research program, funded by "Presidenza del Consiglio dei Ministri, Dipartimento della Protezione Civile" (Italy).

Data Availability Statement: Data available in a publicly accessible repository.

Conflicts of Interest: The authors declare no conflict of interest.

\section{References}

1. Ainalis, D.; Kaufmann, O.; Tshibangu, J.P.; Verlinden, O.; Kouroussis, G. Modelling the Source of Blasting for the Numerical Simulation of Blast-Induced Ground Vibrations: A Review. Rock Mech. Rock Eng. 2017, 50, 171-193. [CrossRef]

2. New, B.M. Ground vibration caused by construction works. Tunn. Undergr. Sp. Technol. Inc. Trenchless 1990, 5, 179-190. [CrossRef]

3. Hashad, A. Using dynamic analysis of site vibration to select the suitable vibration limit. HBRC J. 2018, 14, 180-188. [CrossRef]

4. Rodríguez, R.; Bascompta, M. Vibration analysis and empirical law definition for different equipment in a civil construction. Appl. Sci. 2020, 10, 4689. [CrossRef]

5. Svinkin, M.R. Minimizing construction vibration effects. Pract. Period Struct. Des. Constr. 2004, 9, 108-115. [CrossRef]

6. El Kacimi, A.; Woodward, P.K.; Laghrouche, O.; Medero, G. Time domain 3D finite element modelling of train-induced vibration at high speed. Comput. Geotech. 2013, 118, 66-73. [CrossRef]

7. Connolly, D.P.; Kouroussis, G.; Woodward, P.K.; Alves Costa, P.; Verlinden, O.; Forde, M.C. Field testing and analysis of high speed rail vibrations. Soil. Dyn. Earthq. Eng. 2014, 67, 102-118. [CrossRef]

8. Wang, P.; Yi, Q.; Zhao, C.; Xing, M. Elastic wave propagation characteristics of periodic track structure in high-speed railway. J. Vib. Control 2019, 25, 517-528. [CrossRef]

9. Breccolotti, M.; Materazzi, A.L.; Salciarini, D.; Tamagnini, C.; Ubertini, F. Vibrations induced by the new underground railway line in Palermo, Italy Experimental measurements and FE modeling. In Proceedings of the Eurodyn 2011-8th International Conference on Structural Dynamics, Leuven, Belguim, 4-6 July 2011; pp. 719-726.

10. Crabb, G.I.; Hiller, D.M. Prediction of groundborne vibration from vibrating rollers. Proc. Inst. Civ. Eng. Transp. 2002, 153, 131-140. [CrossRef]

11. Jackson, N.M.; Hammons, M.I.; Walker, R.; Von Quintus, H. Use of Nondestructive Techniques to Estimate the Allowable Vibratory Compaction Level during Construction; State of Florida Department of Transportation: Tallahassee, FL, USA, 2007.

12. Hanson, C.E.; Towers, D.A.; Meister, L. Transit Noise and Vibration Impact Assessment; Department of Transportation: Tallahassee, FL, USA, 2006.

13. Hiller, D.M.; Crabb, G.I. Groundborne Vibrations Caused by Mechanised Construction Works; Transport Research Laboratory: Crowthorne, Berkshire, UK, 2000.

14. Jackson, N.M.; Choubane, D.; Lee, H.; Holzschuher, C.; Hammons, M.I.; Walker, R. Recommended practice for identifying vibration-sensitive work zones based on falling weight deflectometer data. J. Transp. Res. Board 2008, 2081, 139-149. [CrossRef]

15. Cenek, P.D.; Sutherland, A.J.; McIver, I.R. Ground Vibration from Road Construction; New Zeland Transport Agency: Queenstown, New Zealand, 2012.

16. Hendriks, R. Transportation Related Earthborne Vibrations; California Department of Transportation: Sacramento, CA, USA, 2002.

17. Deutsches Institut für Normung. DIN 4150-3: Structural Vibrations-Part 3: Effects of Vibration on Structures. 1999. Available online: https://www.geothermie.de/bibliothek/lexikon-der-geothermie/d/din-4150.html (accessed on 30 December 2020).

18. British Standard 7385-2. Evaluation and Measurement for Vibration in Buildings. Part 2: Guide to Damage Levels from Groundborne Vibration; British Standards Institution: London, UK, 1993. 
19. British Standard 5228-4. Noise Control on Construction and Open Sites-Code of Practice for Noise and Vibration Control Applicable to Piling Operations; British Standards Institution: London, UK, 1992.

20. Swiss Standard VSS-SN640-312a Effet des Ébranlements sur les Constructions; Schweizerische Normen-Vereinigung: Zurich, Switzerland, 1992.

21. UNI 9916:2004. Criteria for the Measurement of Vibrations and the Assessment of their Effects on Buildings; Ente Nazionale Italiano di Unificazione (UNI): Milano, Italy, 2004.

22. NTC 2018. Aggiornamento Delle Norme Tecniche per le Costruzioni. 2018. Available online: https://www.gazzettaufficiale.it/ $\mathrm{eli} / \mathrm{gu} / 2018 / 02 / 20 / 42 / \mathrm{so} / 8 / \mathrm{sg} / \mathrm{pdf}$ (accessed on 30 December 2020).

23. Singh, S.P. Non-Explosive Applications of the PCF Concept for Underground Excavation. Tunn. Undergr. Sp. Technol. 1998, 13, 305-311. [CrossRef]

24. Caldwell, T. A Comparison of Non-Explosive Rock Breaking Techniques. Bachelor's Sci. Thesis, The University of Queensland, Brisbane, Australia, 2004.

25. Zhou, H.; Xie, X.; Feng, Y. Rock breaking methods to replace blasting. IOP Conf. Ser. Mater. Sci. Eng. 2018, 322. [CrossRef]

26. Bieniawsky, Z.T. The geomechanics classification in rock engineering applications. In Proceedings of the 4th ISRM Congress, Montreux, Switzerland, 2-8 September 1979.

27. Uva, G.; Ciampoli, P.L.; Leggieri, V.; Nettis, A.; Ruggieri, S. A mechanical approach for estimating regional fragility curves of existing RC buildings stock in Puglia. In Proceedings of the COMPDYN 2019 7th ECCOMAS Thematic Conference on Computational Methods in Structural Dynamics and Earthquake Engineering, Crete, Greece, 24-26 June 2019.

28. Uva, G.; Sangiorgio, V.; Ciampoli, P.L.; Leggieri, V.; Ruggieri, S. A nuvel rapid survey form for the vulnerability assessment of the existing building stock based on the "Index Building" approach. In Proceedings of the 2019 IEEE International Conference on Systems, Man and Cybernetics (SMC), Bari, Italy, 6-9 October 2019; pp. 976-981.

29. Uva, G.; Leggieri, V.; Morrone, M. Use of data derived by different sources for the seismic vulnerability assessment of current building stock in GIS environment: An application to the municipality of Bisceglie, Italy. In Proceedings of the 3rd International Conference on International Conference on Recent Advances in Nonlinear Design, Resilience and Rehabilitation of Structures, CoRASS 2019, Coimbra, Portugal, 16-18 October 2019.

30. ISTAT. $15^{\circ}$ Censimento Generale Della Popolazione e Delle Abitazioni-9 Ottobre 2011. 2011. Available online: https:/ /www.istat. it/it/files/2012/12/volume_popolazione-legale_XV_censimento_popolazione.pdf (accessed on 30 December 2020).

31. Zuccaro, G.; Dolce, M.; De Gregorio, D.; Speranza, E.; Moroni, C. La Scheda Cartis Per La Caratterizzazione Tipologico- Strutturale Dei Comparti Urbani Costituiti Da Edifici Ordinari. Valutazione dell'esposizione in analisi di rischio sismico. In Proceedings of the 34 Convegno Nazionale GNGTS, Trieste, Italy, 17-19 November 2015; pp. 281-287.

32. Brinkgreve, R.B.J.; Kumarswamy, S.; Swolfs, W.M. PLAXIS 2D 2016; Plaxis bv: Delft, The Netherlands, 2018.

33. Jâky, J. The coefficient of earth pressure at rest. J. Soc. Hung. Archit. Eng. 1944, 30, 355-358.

34. Rayleigh, J. The Theory of Sound; Dover: New York, NY, USA, 1945.

35. Clough, R.W.; Penzien, J. Dynamics of Structures; McGraw-Hill: New York, NY, USA, 1975.

36. Amorosi, A.; Boldini, D.; Elia, G. Parametric study on seismic ground response by finite element modelling. Comput. Geotech. 2010, 37, 515-528. [CrossRef]

37. Lysmer, J.; Kuhlemeyer, R.L. Finite dynamic model for infinite media. J. Eng. Mech. Div. 1969, 90, 859-877.

38. Wiss, J.F. Construction Vibrations: State-of-the-Art. J. Geotech. Div. 1981, 107, 167-181.

39. Torano, J.; Rodriguez, R. Simulation of the Vibrations Produced during the Rock Excavation by Different Methods; WIT Press: Southampton, UK, 2003.

40. Masoumi, H.R.; Degrande, G. Numerical modelling of free field vibrations due to pile driving using a dynamic soil-structure interaction formulation. J. Comput. Appl. Math. 2008, 215, 503-511. [CrossRef]

41. Massarsch, K.R.; Fellenius, B.H. Engineering Assessment of Ground Vibrations Caused by Impact Pile Driving. Geotech. Eng. J. SEAGS AGSSEA 2015, 46, 54-63.

42. Computers and Structures. SAP 2000 Linear and Nonlinear Static and Dynamic Analysis of Three Dimensional Structures; Computers and Structures, Inc.: Berkeley, CA, USA, 2018.

43. Ruggieri, S.; Porco, F.; Uva, G. A Practical Approach for Estimating the Floor Deformability in Existing RC Buildings: Evaluation of the Effects in the Structural Response and Seismic Fragility; Springer: Dordrecht, The Netherlands, 2020; Volume 18. 